\title{
Sobre las arquitecturas salineras de la Bahía de Cádiz
}

\author{
Juan Manuel Suárez-Japón \\ Catedrático de Geografía Humana \\ Universidad Pablo Olavide
}

\begin{abstract}
Resumen
Un modo tradicional de aprovechamiento de los recursos naturales que ofrecía el Parque Natural Bahía de Cádiz ha sido la explotación salinera. Ésta actividad, no solo ha modificado el paisaje original del mismo, sino que ha creado una serie de elementos arquitectónicos, de carácter popular, que han sido adaptados a las necesidades de la explotación. Se puede decir, que la tipología de la Casa Salinera es una consecuencia de los modos de vida y de las prácticas económicas que aseguraron la ocupación de un espacio por los grupos humanos.
\end{abstract}

\section{Palabras clave}

Salinas / Bahía de Cádiz / Arquitectura popular / Casa Salinera / Industria Salinera / Casas bloque / Casas de patio / Acuícultura / Protección Patrimonio Histórico

Hace años, cuando me aproximé al estudio del caserío salinero de la Bahía de Cádiz', advertí que ya aquella investigación era, en buena medida, el fruto de una mirada arqueológica. En efecto, la observación reiterada del estado general de avanzada degradación, -con solo algunas escasas excepciones-, que mostraba una gran parte de estas arquitecturas salineras generó ese primer impulso, esa motivación inicial que siempre se esconde detrás de la elección del tema sobre el que se investiga. Era, entonces como ahora, casi imposible no preguntarse cómo y cuando surgieron aquellas sencillas, esbeltas y frágiles casas; precisar al amparo de qué concreto proceso se produjo la ocupación y el uso humano de aquellos espacios híbridos de mares y de tierras que formaban las marismas del borde de la bahía gaditana; querer fijar también las causas por las que aquella síntesis formal y funcional que se estableció entre la naturaleza del espacio, las demandas del uso y las arquitecturas resultantes que compusieron el paisaje salinero, se quebró dando comienzo desde entonces a una nueva coyuntura en la que estas arquitecturas no han hecho más que avanzar por el camino del abandono, de la degradación física, de la inminencia de sus definitivas ruinas.
Tales interrogantes pueden seguir siendo válidas para acercarnos ahora al conocimiento de las peculiaridades formales de estas arquitecturas salineras de la bahía de Cádiz, así como para actualizar algunas consideraciones sobre su futuro más o menos previsible, un futuro que, en todo caso, estará en conexión directa con aquel por el que discurra el de las propias actividades económicas que explotan este espacio marismeño, pues este es el sino constatado de todas las arquitecturas tradicionales: que surgieron para servir a las demandas que las prácticas y usos económicos de cada espacio planteaban a sus habitantes, -que en muchas ocasiones eran también sus constructores-, que adaptaron sus formas a esas mismas exigencias funcionales y que, finalmente, son víctimas inmediatas de los cambios que en estas se producen. El horizonte actual de gran parte de las viejas arquitecturas rurales ${ }^{2}$, con las que tantos puntos comunes tienen estas casas salineras de Cádiz, nos muestra claramente cuanto acabamos de decir, pues o bien hallamos arquitecturas que siguen en uso, pero que han incorporado elementos extraños para atender a las nuevas formas sobrevenidas en la explotación del espacio, o han acabado por ser abandonadas y desaparecer. Veamos, pues, a la luz de estas consideraciones previas, algunas cuestiones que nos permitan conocer algo de la realidad pasada y presente de estas casas salineras de la Bahía de Cádiz.

\section{Algunas claves metodológicas para el análisis de las casas salineras}

Las arquitecturas tradicionales ${ }^{3}$ admiten, desde luego, diferentes enfoques analíticos e interpretativos, pues atraen el interés de arquitectos, de etnógrafos, de sociólogos o de geógrafos y cada uno de ellos suele ponderar o insistir en ciertos aspectos con preferencia de otros. La opción metodológica de estos últimos, -que es desde la que aquí me sitúo-, ha ido paulatinamente decantándose y precisándose, pasando desde unas iniciales fases meramente descriptivas, hasta otras, más maduras y de mayor rigor científico, en las que se ha buscado también el establecimiento de ciertos niveles explicativos e incluso la elaboración de una teoría interpretativa común. Esta teoría capaz de ofrecer una vía de interpretación de las arquitecturas tradicionales se ha sustentado en algunas ideas básicas;

I. que estas casas son una síntesis y una expresión del modo de vida, del sistema económico de la comunidad que las crea, tanto más claramente cuanto más nos remontemos en el tiempo y nos acerquemos a sus instantes genéticos. En efecto, infinidad de aspectos definidores de dichos modos de vida están pre- 
sentes en la casa popular, desde los materiales constructivos o la orientación dominante que la vinculan al medio físico, hasta la escala de sus diferencias que reflejan las que se dan en las tramas sociales y económicas de la comunidad; sin olvidarnos de los elementos estilísticos o estéticos ${ }^{4}$ que suelen hablarnos también de la pervivencia de tradiciones y formas culturales. En palabras de Pierre Gourou (1979) "la casa rural tradicional precisa en qué medida intervienen los factores físicos y los factores de la civilización en la configuración del paisaje humano", y otro gran maestro de la Geografía gala, Pierre Deffontaine (1972) nos insiste en que "la casa es el reflejo de la vida de esos hombres, de sus esfuerzos, de sus pensamientos, de su grado de evolución";

2. las estructuras formales que ofrecen estas arquitecturas responden a lo que pudiéramos llamar "organicismo funcional", es decir, que el modelo formal, la estructura que finalmente se consolida y se construye, es aquel que responda mejor a las demandas o necesidades que plantean sus propietarios, tanto más cuanto que casi siempre estas arquitecturas han de ser al mismo tiempo viviendas de la familia campesina y prolongación o complemento de sus tareas y labores; es decir, han de servir como viviendas pero también o como graneros, o como cuadras, etc., casi como un apero más al servicio del trabajo de sus dueños o moradores. Pierre George ha sintetizado bien estas ideas afirmando "en la medida en que es una vivienda rural, ya está sometida a dos categorías de condiciones: construida por los propios campesinos es un producto de la civilización técnica regional y de los materiales locales, pero destinada a cobijar no solamente la célula social rural sino un complejo de producción, está adaptada al sistema de cultivo o cría de ganado actual o pretérico; la casa rural es siempre el símbolo de tal sistema".

Este notable cambio de visión acerca del significado de las casas populares o tradicionales ha tenido, naturalmente, su reflejo en las formas de percibirlas y de estudiarlas. De este modo, de un primer momento en que las referencias a las casas se enmarcaban en las alusiones de los elementos "pintorescos" que permitían describir y diferenciar los paisajes regionales ${ }^{5}$, o unas fases en las que se ponderaban sus rasgos geográficos entendidos solo como una respuesta al medio físico en que las casas se insertaban ${ }^{6}$, se ha llegado a propuestas metodológicas en las que priman los aspectos funcionales, es decir, que se asientan en destacar la relación y la dependencia entre la forma de la casa y la función que cumple y cuya manifestación más directa es la disposición y la organización de los distintos espacios que componen la casa. Esta particular organización interior del espacio doméstico tiene una inequívoca expresión gráfica en el plano que es siempre, no lo olvidemos, un elemento de gran valor en todos los estudios de Geografía del Poblamiento.

A partir de la aceptación de estas ideas organicistas y de su aplicación al análisis de las casas rurales, Albert Demangeon elaboró su conocida clasificación tipológi$\mathrm{ca}$, distinguiendo las diversas formas posibles de las que el llamó las "casas bloques" de las que denominaba "casas de corral", ya fueran estos abiertos o cerrados $^{7}$. La síntesis demangeonianas han tenido una general aceptación y sus propuestas de clasificación han sido aplicadas desde entonces en numerosos estudios regionales y monografías centradas en las arquitecturas populares. Pero más allá de cualquier precisión o matización que pudiera plantearse $o$ añadirse a la misma, lo que resulta destacable ahora es que ese enfoque metodológico, basado en la correlación que debe establecerse entre las estructuras formales de cada tipo de casa tradicional, -incluso de las que no lo son-, y las funciones que están llamadas a satisfacer, sigue siendo un principio válido no sólo para comprender la diversidad formal originaria de estas arquitecturas, sino también para analizar y comprender sus procesos evolutivos. Tal es lo que hemos planteado en el análisis de las casas salineras de la bahía gaditana que ahora recuperamos parcialmente en estas páginas.

\section{Una arquitectura para la "industria salinera" gaditana}

El término "industria" se ha aplicado habitualmente para designar al tipo de práctica económica que se ha desarrollado sobre los espacios mareales de la bahía gaditana; en efecto, "industria extractiva", "industria de la sal", han sido formas cotidianas de referirse a estos modos de explotación que, tomando como base la conjunción en estos espacios de las aguas salobres de esteros y caños, con las altas frecuencias de los flujos de vientos y de horas de sol, producían cada año su blanca costra de sales (fig. I), un producto preciado y escaso, por muchos años fuertemente demandado y valorado. Pero pese a esa persistencia del término "industria", es lo cierto que las actividades de extracción salinera poseen rasgos extraordinariamente afines a las puramente agrícolas y es por ello por lo que el estudio de las casas que nacieron y sirvieron a estas prácticas salineras puede acogerse, sin conflicto alguno, a las mismas metodologías utilizadas para las arquitecturas rurales.

I. Los flujos de vientos y el sol sobre las aguas salobres producían cada año la afloración de las blancas costras de sal

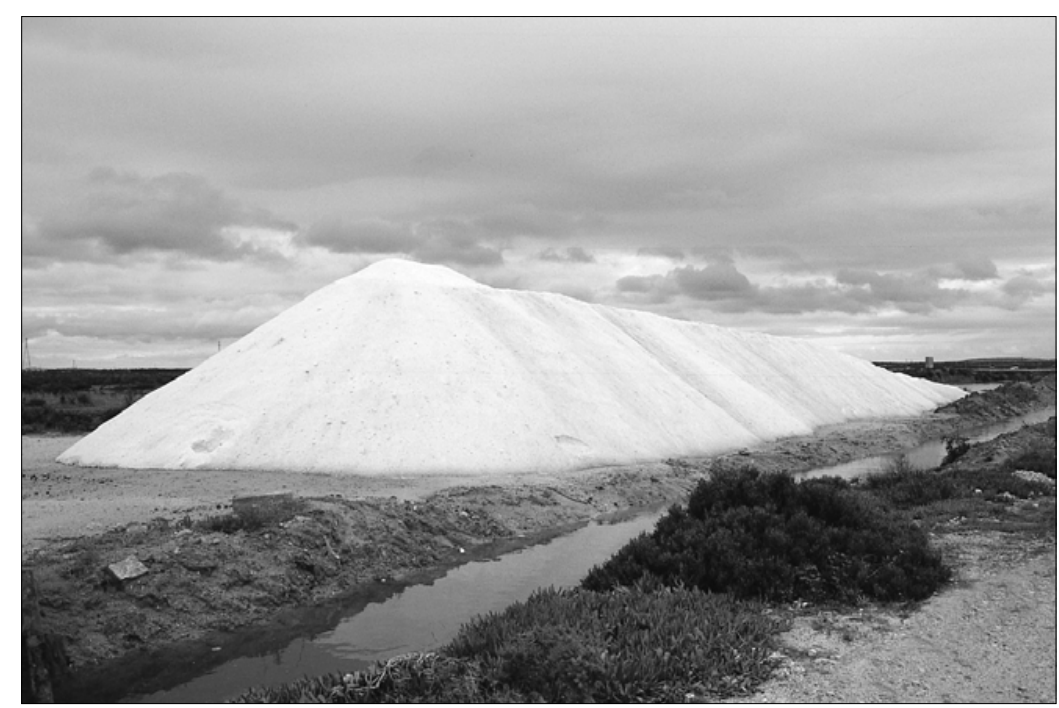


En efecto, la extracción de la sal posee no pocos elementos comunes con las prácticas agrarias: como aquellas, el trabajo de las salinas se desarrolla con una muy directa dependencia de las condiciones naturales, es decir, para ser posible requiere la presencia de determinadas componentes puramente físicas; por otro lado, la salina es también, como los espacios agrarios, el fruto de unas roturaciones ${ }^{8}$, de creaciones y de transformaciones efectuadas por los hombres sobre espacios vírgenes, algo que en el caso gaditano está suficientemente constatado por numerosos estudios que van desde los más lejanos y ya clásicos de Eduardo $\operatorname{Benot}^{9}$ ( I 885), hasta las recientes aportaciones del grupo de investigación coordinado por el profesor Barragán Muñoz (1996). Las salinas, como los campos de labor, dejan finalmente sus cosechas de sales después de no pocas labores de preparación y mantenimiento y exigen también una constante atención incluso en las etapas de pausas productivas. De ahí que aunque la tradición salinera haya acuñado el término de industria, nosotros aceptamos aquí la denominación que propone el profesor Pedro Payán (1987), la de "agricultura mineral", pues bajo la apariencia de esa contradicción de términos se resume muy bien la característica esencial de estas realidades.

Sobre estos espacios y al servicio de estas funciones fue surgiendo una dispersa floración de casas, de edificaciones que, sobre esas llanuras marismeñas de la bahía de Cádiz significaron muy pronto un elemento fundamental en la configuración de su paisaje, un rasgo visible que manifestaba, más que ningún otro hecho, la ocupación que los hombres estaban realizando de estas superficies "anegadizas", de estas hibridaciones de la tierra y el mar, de estos laberínticos médanos de caños y de esteros. Es cierto que "la imagen de estas salinas, de sus inacabables retículos de aguas, de sus montículos blancos y piramidales de sal, de sus airosos y aislados caseríos bajo las trasparencias de la luz de este rincón del sur...es percibida de forma tan nítida como integrante de esta realidad económica y cultural de la bahía gaditana, parece "tan natural", que cuesta trabajo admitir esta reflexión elemental acerca del carácter antrópico y no espontáneo de estas explotaciones" (Suárez Japón, 1989; 38-39). En el mismo sentido apunta Barragán Muñoz $(1996,37)$, cuando admite que aunque estas salinas hayan alterado el medio marismeño original, sin embargo, no lo han "desnaturalizado", y que "si se analizan los componentes abióticos y bióticos de una marisma salinera en contraste con la natural surgen de manera inmediata muchas de las semejanzas que explican su completa integración en el paisaje".

Tal vez por ello, en un paisaje de tales características, donde lo roturado permanece tan cercano a lo natural, las arquitecturas cobren una superior importancia como señal de esa presencia y de esa acción de los hombres. Así ocurre aquí sin duda y aún desde su modestia, estas casas salineras, como todos los hechos de poblamiento, vinieron a ser la más palpable manifestación de las presencias humanas sobre este territorio y de sus actividades y modos de vida. El amplio conocimiento del que hoy disponemos acerca de los momentos históricos y de los mecanismos en que es- ta ocupación de la marisma comenzó a producirse nos sirve por ello, al mismo tiempo, para situar también la propia génesis de estas tipologías arquitectónicas y para aventurar incluso ciertas explicaciones para alguno de sus rasgos identificadores. En este aspecto, cualquier aproximación que podamos hacer al conocimiento de esa dimensión temporal o genética de las arquitecturas salineras de la bahía gaditana, -lo que supone tanto como decir, del comienzo de las propias actividades extractivas-, nos conduce a una aparente sorpresa. De una parte, porque es conocida la importancia que la sal ha tenido históricamente, su condición de valor estratégico e incluso de valor de cambio (Altamira,J., 1948; Stocker,.., 1949; Val, J.M., 1948); de otra, el hecho constatado también de que pese a sus innegables potencialidades para ser explotadas, estas salinas de la Bahía de Cádiz solo comenzaron a ser transformadas con cierta intensidad desde el siglo $X V I I I$, en un proceso cuya culminación pareció producirse en la segunda mitad del XIX, ya que, según las puntualizaciones aportadas por Barragán Muñoz, "la imagen final de paisaje salinero que hoy se conoce, con bastante aproximación fue rematada en torno a 18701880" (1996; 35).

En efecto, resultan ampliamente conocidas las intensas actividades de salazón de pescados y fabricación de "garum" que se desarrollaron en estos litorales atlánticos desde épocas muy remotas (Herrero Lorenzo, MP., 1981; García Bellido, A., 1942) y que nos hacen suponer, con fundamento, que las extracciones de sal fueron practicadas en estas costas gaditanas. Pero todo intento de reconstrucción del proceso de ocupación de las marismas de su bahía y de su transformación en salinas nos conduce a los tiempos medios del siglo XVIII (Torrejón, J., 1996) y sobretodo a ese momento de "furor salinero", del que habla Almeyda (|88I), que se desencadenó desde que en 1869 la Ley de Minas declaró la venta de todas las salinas del Estado y dejó en mayor grado de libertad la fabricación y venta de la sal. Así, un Informe del Cabildo de S. Fernando, fechado en $|8| \mid$, advertía a los salineros acerca del cuidado que debían mostrar en sus labores para no perturbar la libre circulación de las aguas por los caños. El mismo documento, no obstante, señala que las salinas existentes son 22 que, no obstante, proporcionaban el 23'5 \% de la producción salinera nacional (Suárez Japón, JM., 1989; 52 y sgtes.). Años más tarde, en el ya citado estudio de Eduardo Benot, publicado en 1885 , se precisa que las salinas, que en 1823 eran 66, han pasado ya, en 1880, a ser 130, es decir, que se habían duplicado en un periodo de apenas sesenta años. La cifra cobra mayor relevancia aún si la cotejamos con la que arroja el inventario de dichas salinas, -ya sean activas, transformadas o en explotación-, en la actualidad, que Barragán Muñoz fija en 14310, extendidas por algo más de 5,000 Has.

El paisaje salinero de la bahía de Cádiz se gesta, pues, en un periodo que se enmarca en esas dos centurias, de modo tal que en 1880 la marisma está ya casi totalmente ocupada (fig.2), iniciándose dicha colonización por los espacios mareales del fondo de saco de la Bahía y avanzándose después hacia el interior aprove- 
chando como ejes la red de esteros y de caños, especialmente el de Sancti Petri y sus ramificaciones, verdadera arteria vital de esta marisma gaditana. Y como lógico corolario de cuanto hemos señalado, podemos también ahora reseñar que es en ese mismo arco temporal cuando se construyen la mayor parte del caserío salinero, de modo que no es, pues, nada extraño que las casas salineras posean un aire común, fruto de esta similar y pareja biografía. Este es pues, -además del contexto económico y funcional-, el trasfondo de influencias técnicas, culturales o estilísticas en el que debemos situar la explicación de alguno de sus rasgos formales $y$, en definitiva, de sus elementos interpretativos globales.

\section{Presentación del modelo de casa salinera de la bahía de Cádiz: algunos ejemplos}

Las marismas gaditanas en las que se crearon estas explotaciones salineras constituyen, como hemos visto, un espacio no demasiado extenso (5,000 Has.), que se halla enmarcado por diversos e importantes núcleos urbanos: Cádiz, Puerto Real, San Fernando y Chiclana. No obstante y pese a las moderadas distancias existentes entre las explotaciones salineras y estos núcleos urbanos, las condiciones naturales de estos territorios anegadizos hacían muy dificultosos los desplazamientos "I y, finalmente, los salineros optaron por construir sus viviendas en las propias parcelas del salinar que explotaban, dando así lugar al nacimiento de este disperso caserío, cuyas tipologías han venido después a convertirse en elementos y referencias inexcusables de identificación del paisaje marismeño gaditano. Este es un rasgo común de las arquitecturas populares, esa capacidad para conformar un paisaje, para mimetizarse con lo natural hasta el punto de componer un todo difícilmente disociable; lo ha resumido García Mercadal (1930) afirmando que en estos casos "la casa es tan del paisaje como los árboles o los montes: la casa es casi vegetación".

En el momento de realizar el intenso trabajo de campo que nos permitió el establecimiento de estas tipologías 12 ya el estado de conservación de las viviendas era bastante lamentable y los signos del abandono y la degradación se manifestaban claramente ${ }^{13}$, salvo en algunos pocos casos en que el mantenimiento de la actividad productiva, -solo 15 explotaciones en el momento de nuestra investigación-, había conservado mejor la casa. Hoy, pasados algo más de diez años, las pérdidas se han producido ya de un modo general e irreparable, al paso que las viejas salinas dejaban de producir sus blancas cosechas de sales para dejar paso a las más modernas explotaciones de acuiculturas (vid. Barragán Muñoz, 1996). En tal caso, reproducimos aquí las estructuras básicas y las tipologías de las casas salineras de la bahía gaditana tal como las hallamos entonces, acentuando ahora la mirada arqueológica que ya entonces se nos hizo tan necesaria.

En estas casas salineras, como en general sucede con la mayor parte de los arquetipos de viviendas tradicio-

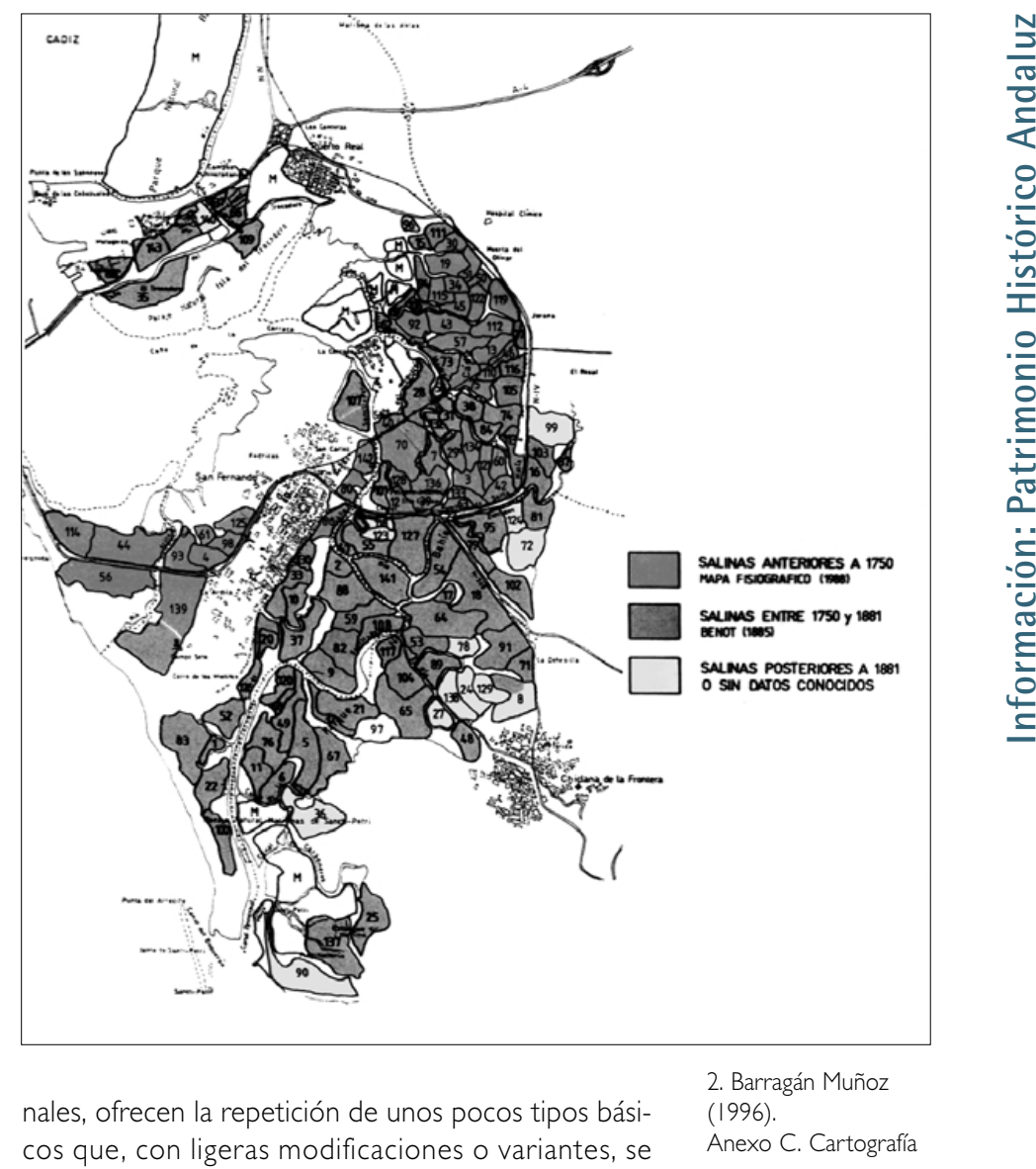

convierten en modelos válidos para comarcas o espacios más o menos homogéneos en cuanto a los modos de vida que en ellos se desarrollan. Tal es lo que sucede aquí, en estas marismas gaditanas, donde nuestro trabajo de campo, que había de enfrentarse a veces con el análisis de restos de viviendas en avanzado estado de degradación, lo que dificultaba grandemente la reconstrucción de los esquemas planimétricos, sin embargo, el hecho de que las mismas soluciones técnicas, la misma combinación de elementos, el mismo o parecido diseño constructivo se repitiera una y otra vez, nos hacía menos aventurada la fijación de la tipología. En todo caso, la fijación de los modelos y los puntos de vista a partir de los cuales se establecían las clasificaciones de las arquitecturas populares, en general, no han dejado de suscitar controversias ${ }^{14}$. Para nosotros, como ya se advirtió, es el enfoque "organicista" el aplicado, un enfoque fundamentado en que las casas populares, como los órganos que proporcionan la vida a los seres vivos, acaban adoptando unas formas y unas estructuras que son la consecuencia de las funciones que están llamadas a realizar. Insistimos, pues ahora, en la conexión entre estructura -formafunción como base metodológica y recuperamos el valor de los planos como expresiones visuales de esa misma relación. El plano refleja, en efecto, la organización de la producción y de la vida de los habitantes de la casa en el momento de la construcción de ésta. La idea, como se puede apreciar, es deudora de las aportaciones de A. Demangeón (1963) y, como él mismo afirma, nunca se entenderá de modo tan rígido que impida incorporar cualquier aspecto diferencial o individualizador que resulte de interés. 


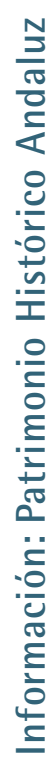

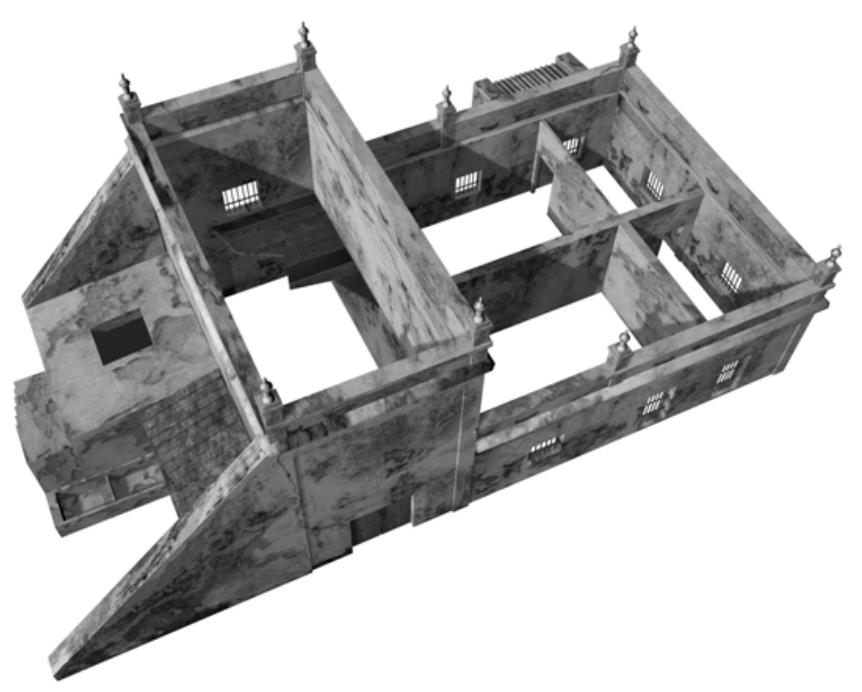

3. Reconstrucción en 3D de lla casa salinera de Cádiz

4. Los alijibes salineros se construyen elevados y exigen una apertura de acceso en el plano superio
Desde un punto de vista global, podemos caracterizar a estas casas salineras señalando ciertos rasgos básicos, capaces de construir un modelo que sirva para dar a conocer el prototipo que mejor defina a estas peculiares arquitecturas, sin que este afán de síntesis que aquí ofrecemos suponga una coincidencia conceptual con J. Robert (1972), cuando sostiene que el geógrafo solo debe centrar su estudio en estas "casas tipo", despreciando el valor de las que, por alguna razón, no encajan del todo en el esquema modelo, lo que el llamaba "casas aberrantes". Así pues, aún con estas necesarias advertencias, procedemos a presentar las que serían características esenciales del modelo de casa salinera de la bahía de Cádiz:

a) presentan dos tipos esenciales, las llamadas "casas bloque" y las "casas de patio", por seguir la terminología demangeoniana. Las primeras son, con claridad, las más abundantes y son aquellas que poseen

(a)

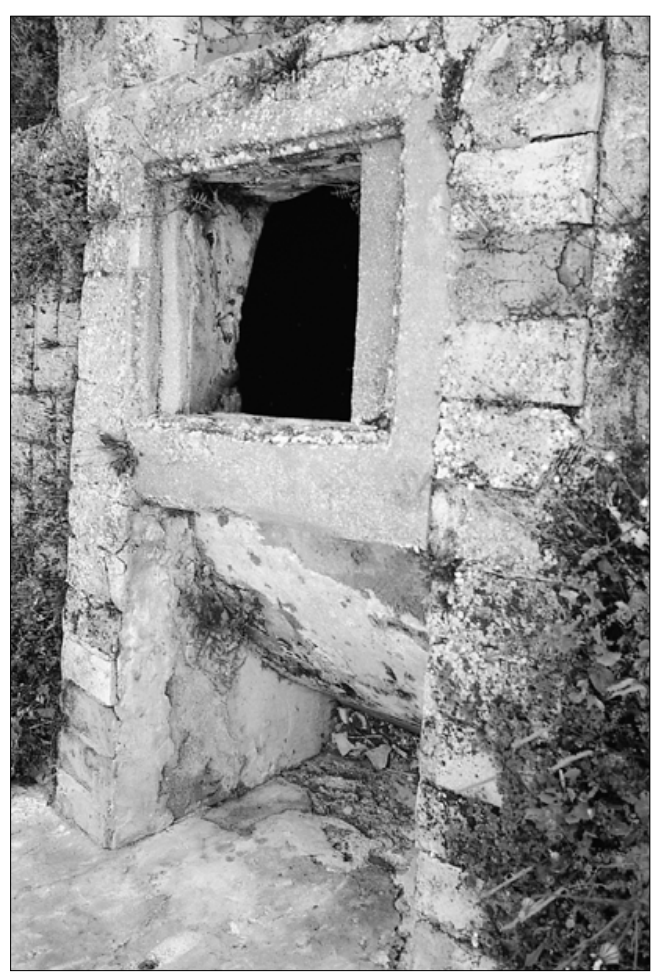

todas sus dependencias bajo una misma estructura de cubierta. Las casas de patio, menos numerosas en el salinar gaditano, donde nunca llegan a alcanzar la complejidad que ofrecen en otros ámbitos andaluces, son las que poseen diversas estancias ligadas a un espacio abierto, más o menos central.

b) sus dimensiones son siempre reducidas, con frentes de fachadas de entre 25 a 35 m, para los lados más largos de sus plantas, con mucha frecuencia son de disposición rectangular. En este rasgo probablemente se manifiesta no sólo el "uso económico de las recursos" que suele ser frecuente en las casas populares más humildes, sino también el hecho de que estas actividades salineras se desarrollaban especialmente al aire libre, haciendo menos precisos grandes espacios internos.

c) todas manifiestan de forma muy clara la dualidad funcional que hemos definido como fundamental en estas arquitecturas populares. En efecto, coexisten bajo un mismo recinto doméstico las estancias destinadas a albergar a los salineros propietarios y a las cuadrillas de trabajadores contratados para la labor y aquellas otras en donde se guardan el ganado o los aperos del trabajo. Una de estas estancias adquiere singular valor, la que sobrepone el pajar -en planta superior-y la cuadra -en el bajo-, siendo la única razón por la que se rompe la dominante línea horizontal que define a estas construcciones, con todas sus estructuras de una sola planta (fig. 3).

d) En estrecha dependencia y como reflejo de una exigencia funcional clara, todas estas casas se dotan también de un aljibe. Este llega a ser, en efecto, un elemento constante y de gran valor identificatorio de estas arquitecturas (Suárez Japón, JM., 1988). La provisión de aguas dulces en ámbitos tan salobres y de tan complejo acceso a los freáticos como las marismas, obligan a este recurso al abastecimiento por las aguas pluviales, cuyo aprovechamiento por vía de los aljibes es también una nota común en los caseríos urbanos de la bahía gaditana. A diferencia de éstos, que suelen excavarse en el fondo de los patios interiores de las viviendas, aquí los aljibes se construyen, adosados a los muros de la misma casa, dotándoseles de complejos mecanismos de conducción de las aguas, mediante bajantes que a veces se insertan entre esos muros y con un acceso en el borde superior (fig. 4), al que se ha de acceder mediante escaleras (fig.5), así mismo, construidas de mampuestos. Estas estructuras de los aljibes se suelen completar con la aparición de pilones adosados, que sirven de abrevaderos a las reatas de animales de carga que viven en la salina.

e) A uno y otro lado de la casa salinera se adosan contrafuertes, que a veces prolongan los muros básicos de la casa y en otras ocasiones se empotran en ellos de forma perpendicular (vid. fig.3). Estos contrafuertes dotan al conjunto de una cierta diversidad, suponiendo una suerte de quiebra de los esquemas monótonos de la construcción, pero sus funciones no son en ningún caso ornamentales, sino 
que se construyen para dotar de mayor solidez a unas construcciones que se elevan sin apenas cimentación y que están constantemente abatidas por fuertes vientos.

f) Una debilidad congénita frente a las agresiones de los agentes externos (vientos, lluvias, calor) a causa de las técnicas dominantes y materiales empleados en su construcción. Elevadas sobre superficies marismeñas, áreas carentes de material de construcción autóctono de suficiente consistencia, las casas salineras se construyen básicamente con materiales de "piedra ostionera" 16, con las cuales se levantan muros de mampostería rústica, de elementos heterométricos (fig.,6) cimentados con capas de adobe y regularizados con la inserción de ripios o ladrillos, todo lo cual es luego cubierto con periódicas capas de encalado, que a un tiempo disimulan la pobreza de sus soportes constructivos y dan al caserío el aspecto de blancura, más deslumbrante sobre los luminosos horizontes de los llanos de la marisma. Las cubiertas son preferentemente de azoteas, construidas con uso de ladrillos sobre viguerías de maderas y rematadas con elementos ornamentales varios sobre los pretiles, de estilos neoclásicos (fig.7) y claramente miméticos respecto a los que, por esos mismos años, se instalaban en una buena parte de las casas populares de San Fernando, Puerto Real o Chiclana 17. Los vanos de las puertas y ventanas se enmarcan en estructuras de maderas, por lo general, escasamente resistentes.

Cualquier selección de tipos de estas casas salineras de la bahía de Cádiz que ahora pudiéramos presentar aquí nos remitirían a descripciones en las que, una y otra vez, estaríamos abocados a referirnos a esos caracteres antes señalados. Si, en general, las arquitecturas populares suelen reiterar los tipos, las soluciones técnicas e incluso los elementos ornamentales, en el caso aquí analizado esa circunstancia se muestra con una claridad notoria. Veamos algunas.

Como prototipos de "Casas bloque", en sus versiones más sencillas, podríamos enmarcar a la casa de la llamada salina de Santa Teresa ${ }^{18}$, situada en el término de Chiclana (fig.8). Posee un planta rectangular, con varios accesos que, no obstante, separan las dos áreas destinadas a los propietarios y a los trabajadores, respectivamente. Una de las crujías alberga la cuadra, que aquí se cubre con un pajar muy bajo. Un contrafuerte se prolonga a ambos lados menores de la vivienda, habiendo sido uno de ellos utilizado para la construcción de un cobertizo. El aljibe, cuyo tamaño es casi igual al de alguna de las estancias interiores, se adosa en un lateral, con su escalera de acceso y su pilón.

Un esquema similar encontramos en la casa de la salina llamada "José y Ana", (también denominada "Rubial Chico"). Es también un modelo de casa bloque, probablemente uno de los más bellos del salinar gaditano 19. Reproduce la planta rectangular, de la que se destacan poderosos contrafuertes, adosado a uno de los cuales aparece un potente aljibe. Como en el modelo descrito, solo la cuadra y el pajar componen
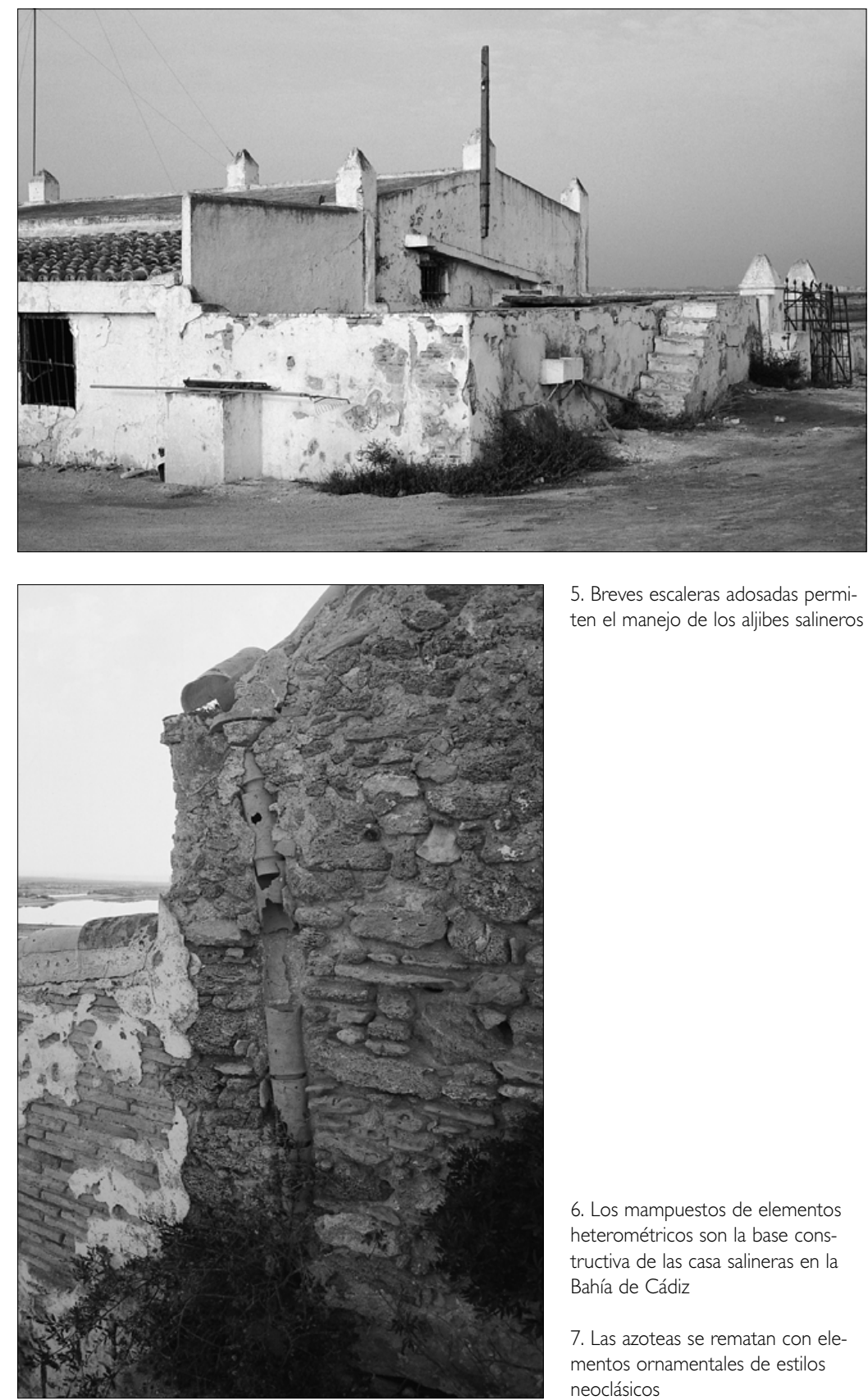

5. Breves escaleras adosadas permiten el manejo de los aljibes salineros

6. Los mampuestos de elementos heterométricos son la base constructiva de las casa salineras en la Bahía de Cádiz

7. Las azoteas se rematan con elementos ornamentales de estilos neoclásicos

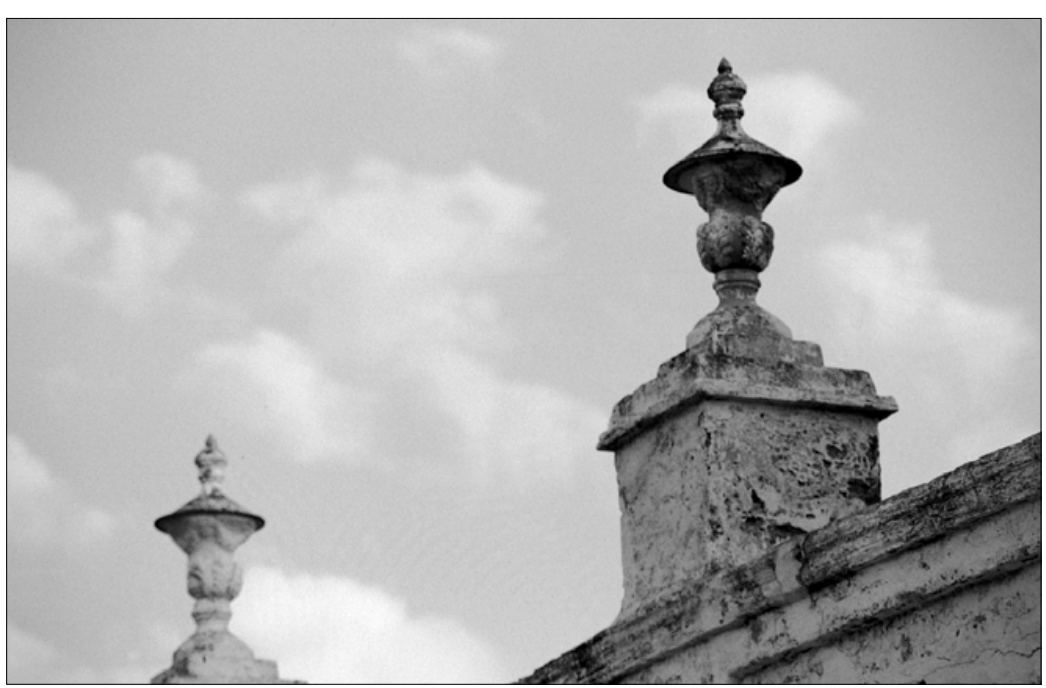




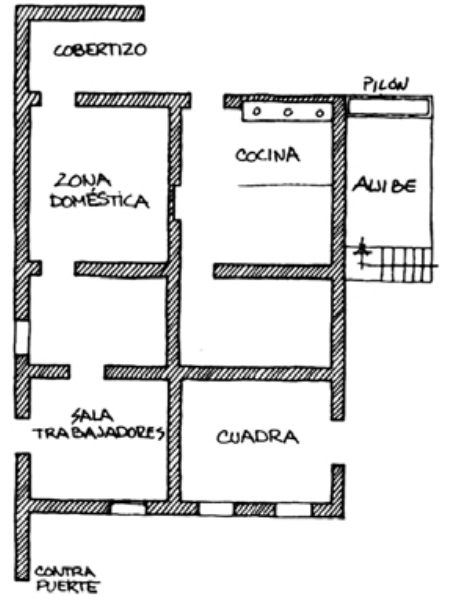

8. Casa de la salina Santa Teresa; un buen ejemplo del modelo de casa-bloque

una crujía de dos plantas, elevándose el cuerpo del mismo sobre la horizontalidad dominante de la vivienda (figs. 9 y 10). La cubierta de terraza o azotea y sus airosos remates sobre los pretiles completan los rasgos más destacados de esta casa salinera. Pese a la reiteración aquí de los mismos elementos, el conjunto posee, no obstante, una elegancia y una esbeltez claramente superior a otras muchas de esta misma tipología de casa - bloque.

Estas casas bloques añaden algunas veces un corral lateral o trasero a su esquema básico; es el caso de las casas de las salinas "San Francisco" (San Fernando) y "Santa María Jesús" o "San Federico" (Chiclana), respectivamente. En otras ocasiones, se construye un porche extendido a lo largo de uno de los flancos más largo del rectángulo de la planta, como en las casas salineras "Pastorita" (Chiclana) y muy especialmente en la "Tres amigos-Río Arillo" (Cádiz) (fig. I I). En todas ellas, sin embargo, se siguen manteniendo los elementos esenciales respecto a las estructuras, materiales, presencia de los aljibes y los contrafuertes, es decir, manteniendo esa especie de "aire de familia" que cohesiona a estas arquitecturas gaditanas.

Respecto a las llamadas "Casas de patio", que ya señalamos que son menos frecuentes en este poblamiento gaditano, reiteremos que el modelo dista bastante del que aparece en las campiñas andaluzas. Se trata de una estructura mucho más modesta, siempre en la forma de patio cerrado que aquí raras veces se dispone en núcleo central, ni alcanza la complejidad de las cortijadas, de tan profundas raíces culturales en nuestra región (Florido Trujillo, G., 1987 y 1996). Frecuentemente, el patio se ubica en un lateral, dentro del esquema longitudinal que domina en la disposición de las casas salineras, dando a veces la apariencia de ser un elemento añadido a lo que primitivamente pudo ser una casa bloque. Es lo que sucede en la salina "Corazón de Jesús" (fig. 12), ubicada en el término de San Fernando. En cambio, una disposición más cercana al modelo de patio central es la que ofrece la casa de la chiclanera salina de "Pastorita", emplazada cerca de Sancti Petri, o la llamada "salina del Pópulo" (fig. 13) de la marisma puertorrealeña. En ambos casos es el patio el que establece la separación entre los espacios domésticos y el doblado de pajar y cuadra. En los dos tipos, así mismo, los aljibes se han construido en relación con los patios, dentro del mismo en el primer caso y fuera, adosado a uno de sus muros, en el segundo. Como se advierte, sigue tratándose de estructuras muy elementales, que en conjunto se siguen disponiendo en una planta rectangular, aunque en estos tipos el patio establezca una solución de continuidad entre las restantes estancias de la casa.

A grandes rasgos, estas serían las tipologías claramente dominantes en el caserío salinero de la bahía de Cádiz, cuya globalidad bien vemos que encaja en el modelo que al principio presentábamos. Llegados a este punto, no obstante, un rasgo más podríamos añadir al citado modelo, una característica también común y reiteradamente presente en casi todas estas casas: nos referimos al estado de abandono y de degradación tan alarmante que presentan, como consecuencia de la acción concertada de la propia desaparición de las actividades extractivas que le dieron vida y razón de ser y de la propia fragilidad de estas construcciones, en las que tan fácilmente hacen estragos la incuria y el descuido a que han estado sometas desde hace décadas. De ahí que, al final, tras el análisis y las descripciones tipológicas, nos restaría una interrogante final:
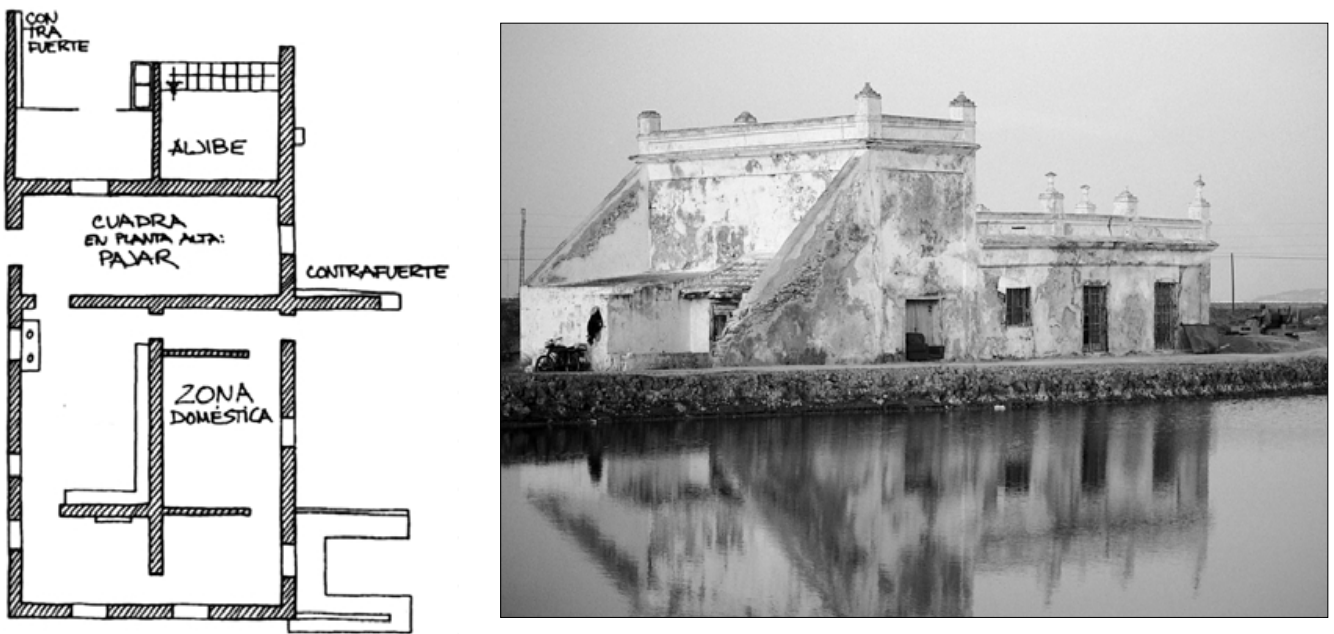


\section{¿Ante la aceptación de un final inevitable?}

Desde la convicción que proporciona la observación y la experiencia, solo un horizonte posible se dibuja hoy para el futuro de estas casas salineras de la bahía gaditana y ese horizonte no admite demasiado espacio para la esperanza. Las casas salineras, ya lo hemos repetido, son una consecuencia y un símbolo de los modos de vida y de las prácticas económicas que aseguran la ocupación de un espacio por los grupos humanos. Sus formas son una derivada de su función. De modo tal que, desaparecida esta o transformada de forma significativa, a las casas no les queda más que la opción "organicista y darwiniana" de adaptarse o el camino lento, pero irreversible, del abandono y la degradación, antesala de su desaparición definitiva. Ha sucedido y está sucediendo con numerosos ejemplares de las arquitecturas rurales de nuestra tierra y está ocurriendo, de un modo acelerado y rotundo, en este caserío salinero de la bahía de Cádiz.

En estas marismas gaditanas, durante tanto tiempo sedes de numerosas explotaciones salineras, el presente $y$, sobretodo el futuro, son ya las explotaciones acuícolas. El viejo salinar ha quedado reducido a unas pocas explotaciones activas ${ }^{20}$, en tanto que los esteros, los caños, las "vueltas de afuera o de periquillo", las tajerías, en suma, el complejo retículo que permitía el anula alumbramiento de las sales, ha sido transformado para albergar ricas producciones pesqueras. Estas nuevas formas económicas, ya claramente dominadoras de estas marismas gaditanas, poseen ante sí un futuro de desarrollo y de consolidación fuera de cualquier duda. Solo se exigen mínimos y necesarios resortes de acomodación a un espacio que figura en su mayor parte bajo la cautela protectora de la figura de Parque Natural. Este es, muy claramente, el diagnóstico que aporta en estudio dirigido por Barragán Muñoz (1996), en el que al mismo tiempo que se acepta el incontrovertible dominio de las nuevas actividades acuícolas, se reclama que éstas se hagan de un modo "racional, como garantes de la integridad física del espacio" (1996; 63). La integridad de las arquitecturas, en cambio, no parece haber suscitado la misma preocupación que el espacio y su progresivo abandono, a causa de su carencia de funcionalidad para los nuevos usos, va produciendo paulatinamente el fin de su presencia física, siendo como son elementos tan esencial del paisaje de estas marismas.

Solo una vía resta, la de la protección al margen de su funcionalidad, su protección como elemento del patrimonio cultural y paisajístico. No obstante, las dificultades para que cualquier iniciativa en esta dirección fructifiquen son también notables. De una parte, son arquitecturas sobre las que no actúa ninguna figura de protección legal y, por otra parte, la inmensa mayoría de ellas, -salvo algunos casos de propiedades municipales-, son propiedades privadas en las que apenas quedan resquicios para intervenir desde las instancias públicas ${ }^{21}$. De modo tal que las perspectivas sobre la conservación de algunos mo-
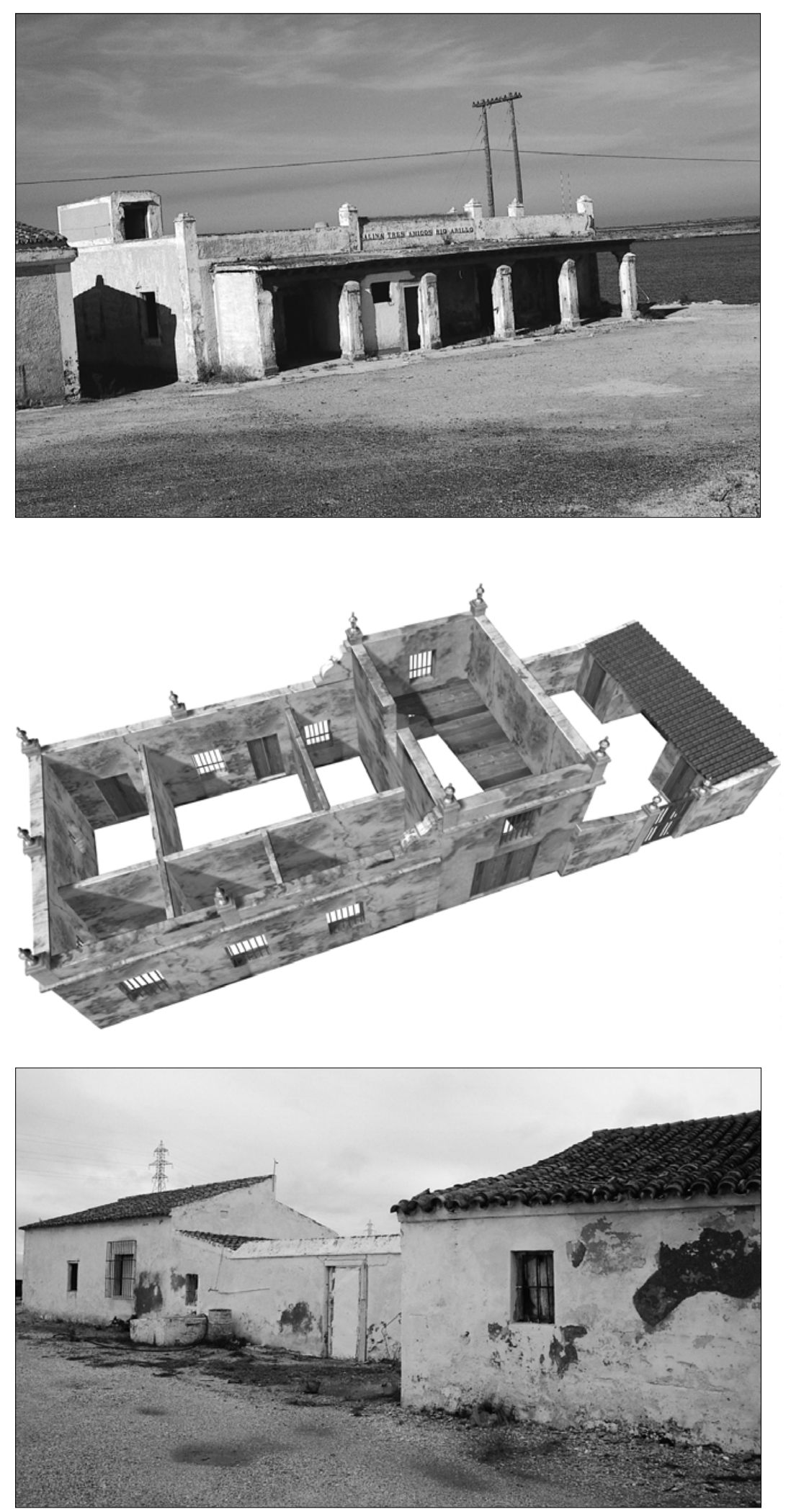

delos de estas arquitecturas populares no pueden ser más que pesimistas, por cuanto hasta ahora nada conocemos que pueda evitar esta progresiva y veloz degradación, porque no queda mucho tiempo y porque siguen sin concretarse proyectos que incorporen con claridad la apuesta por la conservación de estos elementos patrimoniales del paisaje y de la cultura salinera de la bahía de Cádiz.
1 I. La casa de la salina Tres Amigos (Cádiz) responde al modelo de casa-bloque con porches

12. Casa salinera de Corazón de Jesús (San Fernando), en la que aparece un patio ubicado longitudinalmente

13. Casa salinera de patio central 
ALMEYDA BENÍTEZ, J. (| 88 I). Memoria para la limpia de los caños de la Carraca. Tipografía Mercantil. Cádiz.

ALTAMIRA BOLVA, J. (1948). La sal en el mundo. Publ. Industria salinera. Madrid.

BARRAGÁN MUÑOZ, JM. (1983). Aprovechamientos marinos en los terrenos inundables de la Bahía de Cádiz. Diputación Provincial. Cádiz.

BARRAGÁN MUÑOZ, JM. (coord..) (1996). Estudios para la Ordenación, Planificación y Gestión integrada de las zonas húmedas de la Bahía de Cádiz. Oikos-Tau y Universidad de Cádiz. Barcelona.

BENOT, E. (I 885). Memoria de la limpia de la Bahía de Cádiz y Caño del Arsenal. Cádiz.

COLLIN, P. (1965). Changing Ideals in Modern Architecture (17501950). Faber-Faber. Londres.

DEFFONTAINES, P. (1972). L'home et sa maison. Gallimard. Paris.

DEMANGEON, A. (1939). Problemas de Geografía Humana. Paris. (Omega. Madrid. 1963).

FEDUCHI, L. (1978). Itinerarios de Arquitectura Popular Española. 4 volms. Aguilar. Madrid.

FLORIDO TRUJILLO, G. (1996). Hábitat Rural y gran explotación en la Depresión del Guadalquivir. Consejería de Obras Públicas y Transportes. Junta de Andalucía. Sevilla.

GARCÍA BELLIDO, A. (1942). La industria pesquera y conservera en la Antigüedad. Investigación y Progreso. Madrid.

GARCÍA MERCADAL, F. (1930). La casa popular en España. Madrid.
GOUROU, P. (1979). Iniciación a la Geografía Humana. Flammarion/Gustavo Gili. Barcelona.

HERRERO LORENZO, M.P. (1981). Estudio de las salinas de la Bahía de Cádiz. Universidad Complutense. (ejemplar mecanografiado). Madrid.

ROBERT, J. (1972). "La maison agricole. Essai de classification et definition"; en Revista NOROIS. № 75.

RUDOFSKY, B. (1964). Architecture withour architects. Museo de Arte Contemporáneo. Nueva York.

STOCKER, J. (1949). Le sel. P.U.F. Paris.

SUAREZ JAPON, JM. (1982). El Hábitat Rural en la Sierra de Cádiz. Un ensayo de Geografia del Poblamiento. Diputación Provincial de Cádiz. Cádiz.

SUÁREZ JAPÓN, JM. (1988). "El aljibe, un elemento identificador de la casa salinera de la Bahía de Cádiz."; en El Folk-lore Andaluz. Fundación Machado. Sevilla.

SUÁREZ JAPÓN, JM. (1989). La casa salinera de la Bahía de Cádiz. Consejería de Obras Públicas y Transportes; Diputación Provincial de Cádiz y Fundación Machado. Sevilla.

TORREJÓN. J. (1996). "Apartado histórico"; en BARRAGÁN MUÑOZ, JM. (coord.). op.cit.pags. 235-273.

TRICART. J. (s/d). L'habitat Rural. Cours de Geographie Humaine. P.U.F. Paris.

VAL, JM. DE (1948). Geografía de las sales del mar. Estudios Geográficos. Madrid.

\section{Notas}

1. El resultado de aquella investigación, realizada gracias a la ayuda material de la Fundación Machado, de Sevilla, fue el libro La Casa Salinera de la Bahía de Cádiz; editado por la Consejería de Obras Públicas y Transportes y la Diputación de Cádiz, en 1989. (ISBN. 84-86773-10-5).

2. Con posterioridad a la publicación de mi estudio acerca de estas casas salineras han aparecido algunas importantes aportaciones al conocimiento de las arquitecturas tradicionales de Andalucía. Seguramente la obra de Gema Florido Trujillo, Habitat Rural y gran explotación en la depresión del Guadalquivir (Sevilla. 1996) sea la que aborda estos temas con enfoques similares a los que aquí proponemos. En cualquier caso, un rasgo común en todas ellas es la escasa atención -cuando no la pura ignorancia- que se presta a estas tipologías salineras. Tal vez el carácter muy localizado, la escasa extensión territorial por la que se extienden, en suma, su cierta excepcionalidad dentro del panorama general, puede explicar este hecho que aquí solo constatamos.

3. No está ausente de la terminología e incluso de la denominación de estas arquitecturas una cierta polémica. P. Oliver (1978) ha señalado a este respecto que estas arquitecturas han estado tan alejadas de la preocupación de la cultura oficial que ni siquiera se ha buscado un nombre para designarlas; y en efecto, para algunos, el término tradicional es en exceso general y culturalista; otros proponen que se les llamen "arquitecturas vernáculas" (H.R. Hitchcok, 1963; P. Collins, 1965), para destacar su apego a determinadas áreas espaciales, su atadura con la tierra, en el sentido de patria, de origen. Otros, en fin llegan a preferir el nombre de "arquitecturas sin arquitectos" (B. Rudolsky, 1964), para ponderar e hecho de su gestación casi experimental, de manos de alarifes anónimos que concretaron un modelo, luego repetido hasta la saciedad como expresión de un paisaje o de un territorio.

4. Ciertas interpretaciones acerca de las casas tradicionales o populares, sostenidas desde posiciones próximas a los historiadores del arte, afirman que las casas tradicionales no tienen estilo; es más, llegan a rizar la idea afirmando que "su estilo es el de no tener estilo". Ello puede entenderse como una forma de separar a estas construcciones respecto a las que podríamos considerar como "arquitectura culta" en la que se proyectan las variedades estilísticas que se han sucedido en la historia de la cultura, pero en ningún caso eso niega que estos anónimos constructores prescindan de preocupaciones ni de aspiraciones estéticas. Es, por el contrario, un hecho objetivo que en cuanto las casas populares alcanzan un mínimo desarrollo tratan de incorporar algunos exornos o elementos ornamentales, en muchos de los cuales se mimetizan los que presentan las arquitecturas llamadas cultas.

5. El estudio de la bibliografía geográfica francesa, en cuya escuela el análisis del mundo rural alcanzó gran relevancia, permite seguir bien esta evolución. He dedicado algunas páginas a ello, especialmente en el libro El hábitat rural en la Sierra de Cádiz; un ensayo de geografía del poblamiento; (Cádiz. 1982) Diputación Provincial de Cádiz.

6. A este planteamiento responden ciertos ensayos de clasificaciones tipológicas de las casas rurales basadas en los materiales de que estaban construidas; así, se distinguían entre las casas de madera, las de adobes, las de piedras, etc. Vid. Tricart, J.- L'habitat rural. Cours de Géographie Humaine. Paris. (s/d). 
7. Demangeon publicó acerca de estos temas diversos estudios, que fueron recogidos y editados en castellano en Problemas de Geografía Humana; (1939).Omega. Madrid. (1963).

8. Las salinas son realmente estructuras de apariencias sencillas pero que encierran una notable complejidad en su estructura. Todo el sistema está concebido para hacer llegar el agua marina hasta los espacios concretos donde se producirá la obtención de la sal, los llamados "tajerías", y ello se realiza mediante una red complicada de lucios, de caños, de canales que se retuercen, las llamadas "vueltas de periquillo", reduciéndose progresivamente en todos ellos el calado, favoreciéndose la evaporación y, por consiguiente elevando el grado de salinidad del agua. Más detenidamente me he ocupado de estas descripciones en las páginas 36 - 43 de mi estudio sobre el caserío salinero y también pueden verse a este mismo propósito los estudios de Barragán Muñoz (1983 y 1996).

9. El estudio de Benot ( 1885 ) aludía precisamente al deterioro que las continuas roturaciones de nuevas salinas estaban produciendo en los caños que alimentaban las marismas gaditanas. Estos caños se estaban viendo profundamente alterados, aterrándose progresivamente y reduciendo sus calados, precisamente como consecuencias del movimiento de tierras y de las modificaciones introducidas en estos frágiles espacios por la referida creación de salinas. Barragán Muñoz (1996), por su parte, en el estudio que seguramente es la más completa aportación al conocimiento de estos hechos, ha recogido los datos de la primera Anotación Registral de numerosas salinas gaditanas y en todos los casos se alude a que los espacios ocupados eran "tierra que baña el mar", "terreno anegadizo", "terreno salitroso", (pag. 4I) etc., todos los cuales aluden, en efecto, a su condición de marismas naturales previas a las transformaciones en salinas.

10. En mi estudio sobre las arquitecturas salineras señalé que el número final de salinas creadas en el espacio de las marismas de la bahía gaditana era de I30. El estudio de Barragán Muñoz, realizado con posterioridad, lo ha elevado hasta esas 143, cifra tal vez más fiable que la que yo aportaba, dado el carácter mas minucioso y completo que el estudio de Barragán otorga a estos recuentos. En cualquier caso, lo que no se modifica en absoluto es la fijación del momento en que las transformaciones se produjeron de un modo más intenso, y que nos hacen concluir que la creación de este paisaje salinero se efectuó básicamente a lo largo del siglo XIX.

II. Los desplazamientos entre los núcleos urbanos de la corona exterior de la Bahía y muchas explotaciones salineras debían hacerse a través de los caños, en embarcaciones que servían al mismo tiempo para transportar las cosechas de sales y sacarlas al exterior para su comercialización (el llamado Candrays, barco de doble proa, era el tipo más popular y frecuente). Así mismo, recuas de asnos aparejados con grandes sacas eran también un medio de transporte muy utilizado e incluso en algunos momentos y explotaciones se instalaron pequeñas vagonetas que circulaban sobre railes (vid. Suárez Japón, 1989). Todas estas razones, más la de la intensividad y concentración del trabajo que exigían estas actividades, aconsejaban también una presencia continuada de los salineros en sus explotaciones $y$, en consecuencia, la construcción allí de sus viviendas.

I2. El trabajo se realizó a lo largo de los años 1987 y 1988, y bajo mi dirección un grupo de alumnos de la Facultad de Filosofía y Letras de la Universidad de Cádiz rastreó el espacio, analizó viviendas y levantó croquis básicos de los planos, que fueron luego analizados y posteriormente sistematizados. Ya entonces, el número de casas abandonadas era muy elevado y el grado de deterioro de la mayor parte de ellas muy notable. En mi propio estudio aludía ya a la necesidad de aplicar a estas realidades una cierta mirada arqueológica, que hoy, a la vista de la intensa degradación sufrida por el caserío salinero desde entonces, se hace aún más necesaria.

13. Nuestro análisis se fijó en 58 viviendas salineras, que representaban casi el $90 \%$ de las que en esos momentos se mantenían en pie. De ellas, el 58 \% estaba claramente en ruinas, siendo las de los municipios de Chiclana y Puerto Real las que ofrecían un peor estado medio. Solo el $23 \%$ presentaba un estado de conservación calificable como bueno, aunque alguna de ellas ya entonces no estaban habitadas. Nuestra encuesta nos señaló a tan solo 10 casas que estaban habitadas de modo habitual.

14. Los primeros ensayos, todavía con excesiva presencia de las reminiscencias deterministas, se centraban en las tipologías basadas en los materiales constructivos; así, Tricart distinguía las casas de piedra, las de maderas, las de adobes, etc., en relación distintos medios bioclimáticos. Tal propuesta era duramente criticada por P. Gourou (1976), quien no aceptaba el establecimiento de tipologías de casas tradicionales a partir del análisis de uno de sus elementos y postulaba un análisis de las casas en su globalidad. Por su parte, J. Robert (1972) planteó una clasificación a partir de las técnicas de sustentación, hablándonos de casas adosadas, casas elevadas, etc., y más tarde el mismo autor optó por centrarlas en las edades y el consiguiente grado de conservación: casas antiguas, originales, nuevas, renovadas, etc. Para nosotros, como se advierte en el texto, el enfoque organicista que deriva de las aportaciones de Demangeon, es el más adecuado.

15. De hecho, en el análisis tipológico que aportamos en nuestro estudio, ya citado (1996, pags. 78 y siguientes), presentamos una diversidad que trata de acoger, justamente, tanto a las arquitecturas más claramente insertas en el modelo, como a las que se escapan de él.

16. Se trata de una caliza de origen marino, extraída de los fondos de materiales finiterciarios que suelen aparecer en algunas áreas de la bahía. Se trata, por otra parte, del material con el que se han construido gran parte de las arquitecturas urbanas de las ciudades de la bahía.

17. Este mimetismo de los elementos ornamentales o de aquellos que remedan los utilizados en los llamados estilos clásicos, es un rasgo que Luis Feducci (1978) atribuye a la arquitectura popular en general. En este caso de las casas salineras de la bahía de Cádiz estos ornamentos suelen recordar a los estilos barrocos y, sobretodo neoclásicos que tan presentes estaban en las arquitecturas urbanas de la época.

18. La toponimia de las salinas es un tema interesante. En numerosos casos plantean dificultades al investigador, porque el nombre que aparece en los documentos no coincide con el que le atribuye el común de las gentes. En todo caso, hay un predominio exagerado de nombres con alusiones a advocaciones religiosas, especialmente de santos. (vid. Barragán Muñoz, 1996).

19. Situada al borde la carretera entre San Fernando y Chiclana, esta localización ha permitido a cualquier pasajero ver que su degradación en los últimos años ha sido muy fuerte. Hemos sentido entonces la impotencia de ver como se descarnaban sus muros, como se rompían sus airosos adornos de los pretiles de la azotea, como desaparecían sus rejas.., como se cerraba una página bellísima de una historia cultural centenaria.

20. El estudio de JM. Barragán Muñoz (1996;46 y sgtes.) solo registraba I| explotaciones activas en el año 1994, con solo 56 obreros empleados en las labores de producción. De estas II, los términos de Cádiz y Puerto de Santa María solo tenían I cada uno; en tanto que Chiclana conservaba 3, Puerto Real, 4 y San Fernando, 2.

21. Fui parte en frustrados intentos para adquirir, por parte de la administración, alguna de esas viviendas con el fin de reutilizarlas en el marco de los usos públicos del Parque Natural Bahía de Cádiz. Así mismo, conozco las proyectadas intervenciones del Ayuntamiento de Chiclana respecto a la conservación de uno de los caseríos salineros ubicados en su término, aún sin concretarse en el momento de escribir estas líneas. 